\title{
Stakeholder participation in the distribution of freshwater in the Netherlands
}

\author{
Joanne Vinke-de Kruijf • Saskia Hommes • \\ Geiske Bouma
}

Published online: 20 August 2010

(C) The Author(s) 2010. This article is published with open access at Springerlink.com

\begin{abstract}
It is widely recognized that integrated approaches are required to manage our limited water resources in an effective and sustainable manner. In the Netherlands, this is mostly realized by organizing integrated spatial development processes. This paper presents a discussion in which the distribution of freshwater is integrated with spatial development in the southwestern Delta in the Netherlands. This discussion is characterized by uncertainty in knowledge and stakeholders with diverging perceptions. By actively involving these stakeholders in a process of problem structuring, it was possible to reach an agreement on the preferred direction for solutions. Problem-structuring involves that stakeholders actively participate in formulating the problem and its solutions. It is characterized by interaction between stakeholders and the integration of expert knowledge and stakeholder knowledge. Based on these practical experiences, we conclude that putting integrated water management into practice benefits from a problem-structuring approach. This enhances learning processes and contributes to the development of an agreed upon and valid knowledge base. As the context of such processes is highly dynamic, there is a need for transparent and adaptive process management.
\end{abstract}

Keywords Problem structuring - Water management - Negotiated knowledge - Freshwater Agriculture $\cdot$ Case study

J. Vinke-de Kruijf $(\bowtie)$

Department of Water Engineering and Management \& Twente Centre for Studies in Technology and Sustainable Development, University of Twente, P.O. Box 217, 7500 AE Enschede, The Netherlands e-mail: joanne.vinke@utwente.nl

S. Hommes

Unit Scenarios and Policy Analysis, Deltares, P.O. Box 85467, 3508 AL Utrecht, The Netherlands

G. Bouma

Built Environment and Geosciences, Business Unit Innovation and Environment, The Netherlands Organization for Applied Scientific Research (TNO), P.O. Box 49, 2600 AA Delft, The Netherlands 


\section{Introduction}

Around the world, the pressure on freshwater resources and related uncertainties are increasing as a result of socio-economic developments and climate change (Dewulf et al. 2005). Agriculture is one of the sectors that is directly affected by these changes. Vice versa, agricultural water use also directly affects the natural system as a whole. Hence, agricultural water issues should be approached in an integrated manner (cf. Abdeldayem et al. 2005). Since the implementation of the Water Framework Directive (WFD), integration has become a central concept in water management in Europe. This directive explicitly includes integration of various objectives, water uses, disciplines and legislation (European Commission 2003). In this contribution, we present an example how Integrated Water Resources Management (IWRM) is implemented in the Netherlands. In this country, IWRM is often realized by organizing integrated spatial development processes in which water management issues are connected to other user functions, such as housing, nature and recreation. Implementation of water policy is preferably done in cooperation with all relevant stakeholders in area-specific processes (Min. V\&W 2007, 2009). The problems addressed in such processes are typically characterized by uncertainty, complexity and disagreement (Kolkman et al. 2005). Such complex, unstructured problems benefit from a problemstructuring or learning-oriented approach (Hisschemöller 2005; Hommes et al. 2009b). Problem-structuring refers to "one or multiple rounds of interaction in which actors actively participate in the formulation of a problem and its solutions" (Hommes et al. 2009b).

This paper presents two case studies, which are both part of a fundamental discussion about the distribution of freshwater in the southwestern Delta in the Netherlands. In both case studies a problem-structuring approach was adopted to deal with this issue. This paper aims to present how processes of problem-structuring develop. Furthermore, we aim to draw lessons regarding the design and management of these processes, including the management of contextual factors. This paper is organized as follows. "Theoretical framework and research methodology" presents the theoretical framework and the research methodology, which are used to analyze the case studies. In "Case study description: freshwater distribution in the Southwest of the Netherlands", the two case studies are illustrated. An analysis and discussion of the case study results is presented in "Results and discussion: design and management of stakeholder involvement". The last section presents our conclusions regarding the management of integrated processes.

\section{Theoretical framework and research methodology}

Active involvement of stakeholders in problem-structuring

Problem-structuring aims to identify, confront and (if possible) integrate divergent views with respect to a given problem situation (Hisschemöller 2005). It requires the active involvement of relevant stakeholders. Stakeholders are persons, groups or organizations that are directly affected by actions taken to deal with an issue. The fact that they are directly affected or influenced by an issue, is what distinguishes stakeholders from the general public. Active stakeholder involvement is no legal obligation. The WFD, for example, only requires access to background information and consultation. In addition, it encourages the active involvement of all interested parties. This implies that "stakeholders are invited to contribute actively to the process and thus play a role in advising the competent authorities" (European Commission 2003 p. 26). 
IWRM projects often address complex, unstructured water problems. These are problems for which knowledge is uncertain and perceptions of stakeholders involved are diverging and sometimes conflicting (Hommes et al. 2009b). Perceptions encompass ideas about facts, interests, norms and values, regarding their environment and the problems and opportunities within it (Koppenjan and Klijn 2004; Schön and Rein 1994). Stakeholders' perceptions often diverge because they have divergent interests and perceptions of reality, and thus different objectives (Van de Riet 2003). The aim of problem-structuring is that stakeholders develop - through communication and interaction - a joint formulation of the problem and its solutions, i.e. a problem-solution combination (Hommes et al. 2009b). Ideally, this problem-solution is based on 'negotiated knowledge', i.e. a knowledge base for which stakeholders agree about its validity and about its significance and meaning (Koppenjan and Klijn 2004). Developing this requires that stakeholders go through processes of cognitive and strategic learning. Cognitive learning refers to stakeholders' increased knowledge and insight about the nature, causes and effects of the problem, possible problem-solution combinations, and their consequences. Strategic learning refers to stakeholders' increased awareness about the involvement of other parties and mutual dependencies (Hommes et al. 2009b; Koppenjan and Klijn 2004). Furthermore, the created knowledge base needs to be context-specific. This knowledge is often not ready available and needs to be constructed by giving meaning to existing sources of knowledge. This requires the integration of: (1) practical knowledge grounded in practical experiences; and (2) expert knowledge grounded in scientific models, statistics and sophisticated models based on (scientific) research (Eshuis and Stuiver 2005; Hommes et al. 2009b).

\section{Contextual factors}

Problem-structuring does not take place in isolation; it influences and is influenced by a dynamic context. Bressers (2009) distinguishes between three contextual layers that may exert an influence on an interactive process: a project-specific, structural and wider context. The project-specific context refers to the specific circumstances and history of a process. It includes decisions and choices related to the establishment of objectives, the choice of instruments and resources, and the time schedule. This project-specific context forms the direct input and sometimes even the starting-point of a process. The structural context concerns the institutional regime in which a process is embedded. The two main elements in this context are: governance and property and use rights. Governance refers to the idea that resources are managed through the interaction between many actors at multiple levels. Property and use rights are the rules and regulations determining the accessibility of a water system for various users and uses (Bressers and Kuks 2004). Around the structural context of a process there is still a wider physical problem context, which includes political, economic, cultural and technological aspects. This wider context often exerts a more indirect influence on the process, but may also have a direct influence on the process.

One of the main risks of interactive processes is that parties start to negotiate, but that it ends in no decision or that the results are not used (Abels 2007; De Bruijn et al. 2002). It is argued that as interactive processes are often poorly connected to the formal politicaladministrative structure (the governance system), their impact has still been very limited (cf. Abels 2007; Klijn and Koppenjan 2000). This relates on the one hand to the fragmentation of decision-making and on the other hand to the involvement of politicians (Hommes 2008). This raises the question: who should be involved and how? According to Wesselink (2007) an interactive process can only generate implementable outcomes if it takes into account the interests of: (1) actors that live and work in the area: they have 
hindrance power in formal procedures; (2) actors with administrative responsibilities in the area: they want a decision to be taken; and (3) actors at national (or regional) politicaladministrative level: a decision needs to fit within ongoing policy, should be politically defensible and count on financial resources. We further discuss who should be involved in problem-structuring in "Results and discussion: design and management of stakeholder involvement".

\section{Analytical framework}

The previous subsections provided an overview of the main theoretical concepts underlying our case study research. The resulting analytical framework, which will guide the case study description and analysis ("Results and discussion: design and management of stakeholder involvement" and "Conclusions"), is schematized in Fig. 1. Its two main components are: contextual setting and interactive process. As regards the contextual setting, attention is paid to the wider, structural and project-specific context (see "Contextual factors"). The description of the interactive process, the second component, focuses on the evolution and outcomes of problem-structuring (see "Active involvement of stakeholders in problem-structuring" and "Contextual factors").

Research methodology

The strategy used for this research is qualitative case study research. The rationale behind this strategy is that 'how' and 'why' questions are addressed concerning real-life processes for which no clear boundaries exist between process and context (Yin 2009). This paper is based on two case studies, which are both part of a fundamental discussion on the freshwater situation in the Southwest of the Netherlands. The in-depth analysis is based on the following data sources: (1) observations by researchers and process managers; (2) written material, such as research reports, project documents, policy documents, email conversations and newspaper articles; (3) chances and bottlenecks (related to various freshwater scenarios), ideas and preferences written down by process participants during various workshop sessions; and (4) interviews carried out by the process managers before the process (Case 1 and 2) and by other academic researchers after the process (Case 1).

The role of the authors differed in each of these case studies. For the first case study, research activities were mainly undertaken by two of the authors who adopted the traditional role of academic researcher. They were involved as observer during various interactive sessions, while the other author was involved as a process manager. The second

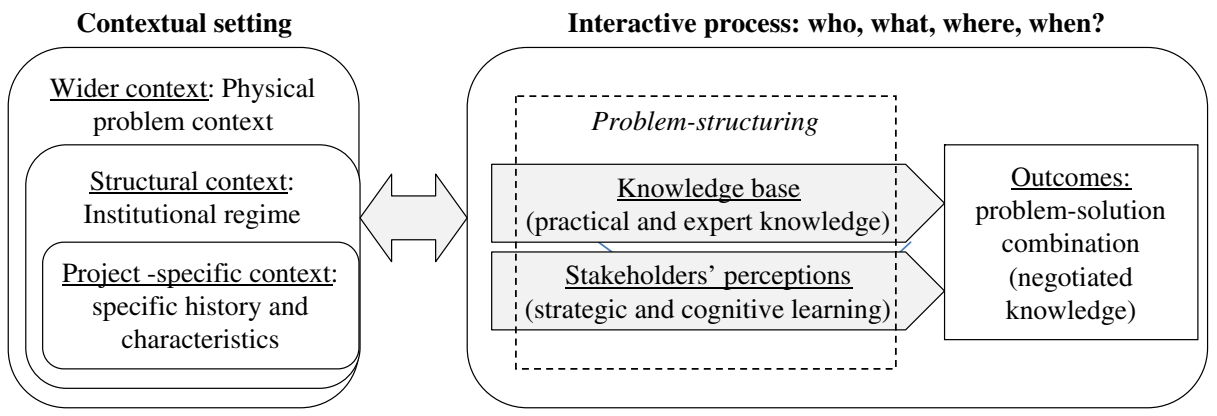

Fig. 1 Analytical framework for problem-structuring in context (adapted after: Hommes et al. 2009b) 
case study was rather an example of action research or action science. In action science, researchers adopt the role of active consultant. Action scientists test and modify theory through action and influence the process under study. One of the main benefits of integrating the role of researcher and consultant-within a single project and between projects - is that it provides better access to case studies (Gummesson 2000). The authors also used data collected by other academic researchers and process managers, who were involved in research activities within the context of the knowledge development program 'Living with Water'.

\section{Case study description: freshwater distribution in the Southwest of the Netherlands}

\section{Contextual setting}

\section{Wider context: freshwater supply in the southwestern Delta}

The physical context of the case studies is the so-called Delta area, which is located in the southwest of the Netherlands. Following a destructive flood in 1953, the Dutch Government decided to realize a series of constructions to protect this area from the sea. These Delta-works made the Delta safer, more accessible and created several freshwater lakes, which provided opportunities for drinking water supply and agriculture. As a result, several agrarians started to invest in modern irrigation techniques, which allow them to grow high-quality vegetables and fruits. Other agrarians still grow more traditional crops (corn, potatoes and sugar beet) and are independent of freshwater. Unfortunately, the Delta Works also resulted in a degradation of the water quality and in ecological problems. One of these ecological problems is the excessive growth of blue-green algae (cyanobacteria) in the freshwater Volkerak-Zoom lake (VZ-lake, Fig. 2). Agrarians who are dependent on freshwater are negatively affected by this excessive blue-green algae growth as it often prevents the intake of freshwater during summer.

The present National Spatial Planning Strategy regards re-establishment of estuarine dynamics as "an important solution both for a sustainable restoration of the ecological

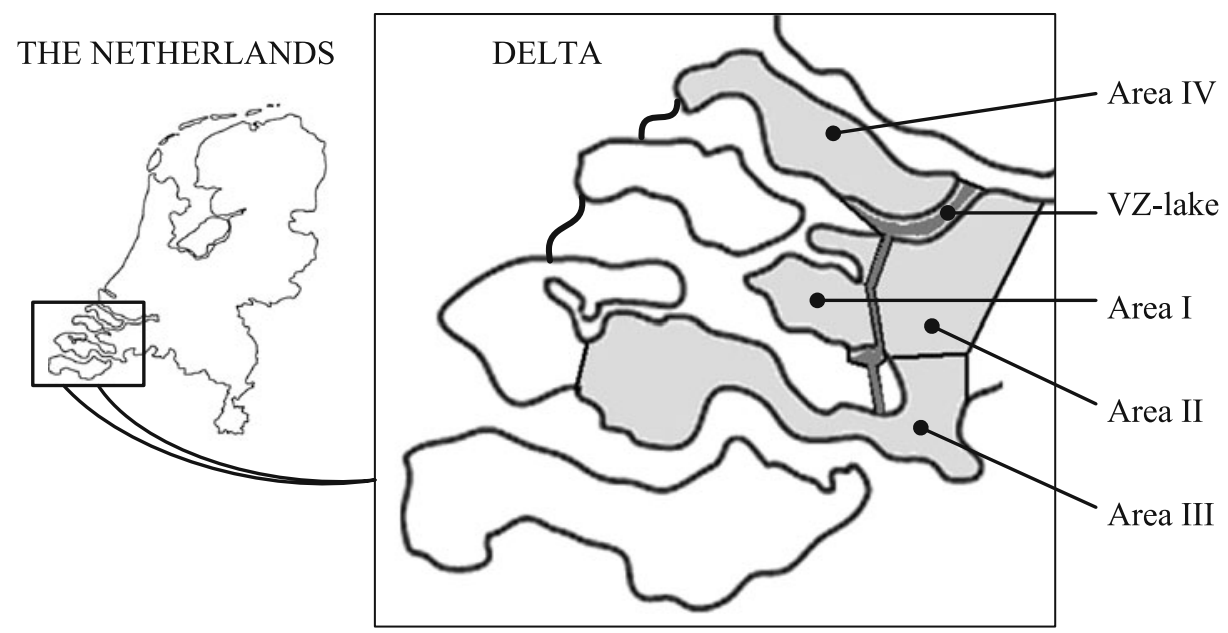

Fig. 2 The location of the Delta, the VZ-lake and the four area-specific discussions 
quality, the preservation of safety against flooding, and the transportation over water" (Min. VROM et al. 2004 p. 31). Recently, this direction for solutions was confirmed by the outcomes of the Planning Study VZ-lake. ${ }^{1}$ Transforming the freshwater VZ-lake into a saltwater (or brackish) lake by re-establishing estuarine dynamics, will have a considerable impact on the freshwater supply for drinking water, local nature (on the islands) and agriculture. It may affect all agrarians in the region-dependent and less dependent on freshwater-as it will change the freshwater situation and may increase saline intrusion.

\section{Structural context: ongoing policy processes}

In 2000, the Dutch government decided to put ajar one of the sluices in the Delta region as from 2005. Among the reasons for this 'ajar decision' were improvement of the ecosystem and compliance with international agreements. The decision raised many questions, among others about its consequences on freshwater supply for agriculture, and further research was therefore undertaken. It is currently foreseen that the sluice will be put ajar by the end of 2010. The 'ajar decision' also raised questions about further re-establishment of estuarine dynamics and its consequences for freshwater supply. In 2003, the state secretaries of the Ministry of Transport, Public Works and Water Management (Min. V\&W) and the Ministry of Agriculture, Nature and Food Quality (Min. LNV) sent a letter to the three Provinces located in the Delta region, in which they officially informed them about the 'ajar decision'. In the same letter, the three Delta provinces were also asked to start a fundamental discussion, with various stakeholders, about connecting a more natural Delta with a more natural, sustainable freshwater situation for agriculture. When this request came, the Delta provinces already developed an integrated vision on a sustainable Delta, which pays attention to safety, economy, social well-being and ecology. This vision includes the reestablishment of estuarine dynamics in the whole Delta within 30 years (Provincie Zeeland 2003). In 2004, a Delta Steering Group ${ }^{2}$ was established to implement this vision. The agenda of this Steering Group includes the Planning Study VZ-lake and a fundamental discussion on regional freshwater supply.

The fundamental discussion and the Planning Study VZ-lake are separate, but closely interlinked processes. The Planning Study is governed by an administrative council consisting of above-mentioned Ministries, three provinces, three water boards and seven municipalities. The study aims to solve the blue-green algae problem in the VZ-lake before 2015. In 2006, it appeared that only a saltwater VZ-lake provides a solution for the bluegreen algae problem. Final decisions regarding the future of the VZ-lake and the freshwater supply in the area are under the authority of the national government. At the end of 2009, the national government approved the National Water Plan 2009-2015. This plan states that saltwater will be let into the VZ-lake before 2015. Investigations on freshwater supply in the area will be continued. A final decision on the realization of estuarine dynamics in the VZ-lake is expected in 2012 (Min. V\&W 2009).

\footnotetext{
${ }^{1}$ The poor water quality of the VZ-lake has been a problem for years. Therefore, the Administrative Council Krammer-Volkerak (BOKV) was established. The Planning Study aims to solve the blue-green algae problem in the VZ-lake before 2015.

${ }^{2}$ Before 2008 this steering group was known as the Delta Council (in Dutch: Deltaraad).
} 


\section{Project-specific context: objectives and status of the fundamental discussion}

The Delta Steering Group decided to divide the fundamental discussion into four local, area-specific discussions (see Fig. 2). The demarcation of these areas is based on characteristics of the natural system. The results of these discussions were integrated by the Delta Steering Group and sent as an advice to the Min. V\&W and the Min. LNV in May 2009. Table 1 provides an overview of all four sub-discussions in time. The remainder of this paper focuses on the sub-discussions in area I and III, respectively, case study 1 and case study 2.

The objective of both discussions was 'to develop a shared insight and agreement about the most desirable directions for solutions or development' and 'involve all relevant parties'. The Delta Steering Group stated that the discussions should include the impacts of climate change, developments in the agricultural sector and possible changes in the water system. The selection of participants was based on criteria similar to Wesselink (2007). The following actors groups were involved: (1) actors with a direct stake in freshwater supply; (2) actors with administrative responsibilities; and (3) actors participating in decisionmaking. Boundary condition for participation was commitment to the process design. After discussing chances and bottlenecks (phase 1), solutions would be generated (phase 2) and impacts would be assessed (phase 3). Every phase starts with a broad scope (diverging), which is than narrowed down (converging). Process input may concern expertise, politics, interests and (financial) resources (see Fig. 3).

\section{Sub-discussion Tholen \& St. Philipsland (area I)}

The first case study (area 1) consisted of three plenary workshops and several sectorspecific meetings (see Fig. 4). In total, approximately 22 persons participated in the process. These participants represented the following actor groups: (1) agrarians (association and individuals, 11 persons) and nature protection (associations and area managers, five persons); (2) municipality and water board (four persons); (3) Min. V\&W and province (two persons).

Prior to the start of the process, the project team had prepared an area-specific note summarizing the results of previous studies (expert knowledge) and of interviews with stakeholders in the area. During the kick-off meeting, especially the agrarians reacted with great skepticism to the area-specific note and the process design. The design included that the discussion would concentrate on three future scenarios for the VZ-lake: autonomous development; freshwater lake (without blue-green algae); and re-establishment of estuarine dynamics. The latter scenario was no option for many economy-oriented actors (agriculture sector). But, it was also the only reasonable scenario for many ecology-oriented actors

Table 1 The time plan of the freshwater discussion

\begin{tabular}{ll}
\hline Period & Activity \\
\hline May-November 2006 & Sub-discussion in area I (Case 1) \\
October 2007-April 2008 & Sub-discussion in area II \\
June 2008-May 2009 & Sub-discussion in area III (Case 2) \\
End 2008-June 2009 & Sub-discussion in area IV \\
June 2009 & Integration of results and reporting
\end{tabular}




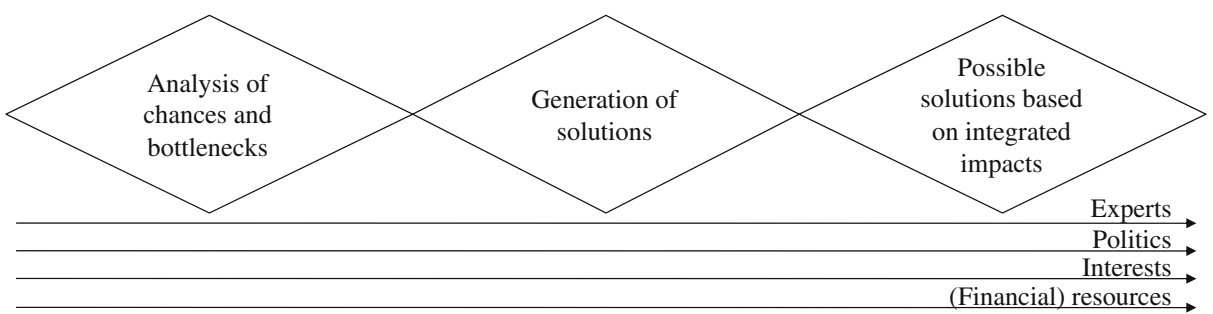

Fig. 3 Process design for sub-discussion in area I and III

(nature sector). Stakeholders of these groups clearly behold diverging and sometimes conflicting problem perceptions. At the same time, most of them were affected by the excessive growth of blue-green algae in the VZ-lake in summer. For the nature sector, it formed an ecological problem, for the agricultural sector an economic problem (freshwater was cut off during summer) and for governmental actors a mix of problems (related to e.g. economy, recreation, ecology and livability).

During the first workshop, which started with an area visit, participants were asked to formulate, cluster and prioritize chances and bottlenecks for the formulated scenarios. Because of their diverging perceptions, each participants came up with other chances and bottlenecks. The period following the workshop was used by the project team to answer, in cooperation with participants, various knowledge questions that were not answered in existing studies. The project team organized sector-specific meetings in which solutions were generated and their impact on agriculture, nature and society was assessed. During this period, practical knowledge was contributed by the agricultural sector about agricultural impacts, by the nature sector about ecological impacts and by the water board about the realization (feasibility and costs) of the freshwater supply.

In the last workshop the participants were asked to vote for their preferred direction for solutions. Initially, the workshop resulted in two desirable directions for solutions, one for a freshwater VZ-lake and one for a saltwater VZ-lake. The process managers, however, urged the participants to reach an agreement on one solution, because an agreed solution was requested by the Delta Steering Group and would be a very strong result. They pointed out that the Planning Study VZ-lake showed that the freshwater scenario could not solve the water quality problems on the long term. Considering this, an agreement could only be reached if re-establishment of estuarine dynamics would be combined with an alternative freshwater supply would be constructed. Eventually, participating stakeholders from the agricultural and nature sector wanted to lay down in a covenant that the most desirable direction for solution would be the construction of an alternative freshwater supply prior to re-establishment of estuarine dynamics. This conclusion was supported by calculations of the required freshwater supply capacity and rough estimates of costs and benefits.

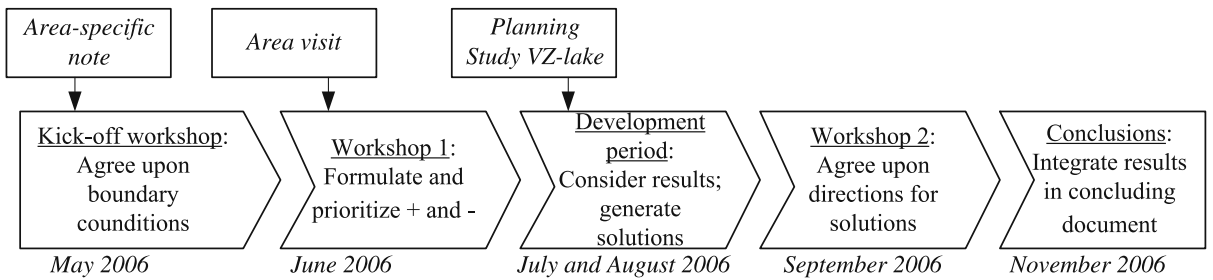

Fig. 4 Rounds of interaction for the sub-discussion in area I 
Sub-discussion South Zeeland and West Brabant (area III)

The second case study (area III) consisted of two plenary workshops and various sectorspecific meetings (see Fig. 5). The number of participants was approximately 49, which is considerably more than in area I. They represented the following actor groups: (1) agrarians (association and individuals, ten persons), nature protection (associations and area managers, seven persons), drinking water companies (two persons) and a golf club (two persons); (2) five municipalities and two water boards (15 persons); (3) Min. V\&W, Min. LNV and two provinces (13 persons).

Area III covers two administrative territories (provinces) and includes three sub-areas using freshwater from different sources. Only one of the areas extracts freshwater from the VZ-lake. The areas were integrated in one discussion because the potential of one of the area's freshwater sources, the so-called 'Brabant Wall', was not fully used yet. It was expected that its unused freshwater potential could provide a solution for freshwater supply in the other two areas. Much information (expert knowledge) on this freshwater source was already available, but not yet distributed among the stakeholders. Also for this project, it was decided to summarize available information in an area-specific note. In developing this note, it became clear that all participating stakeholders wanted to benefit from this freshwater. Two provinces, nature organizations, a drinking water company and agrarians all wanted to use the freshwater potential in their own interest. Also the individual farmers had different interests: the farmers that grow high-quality vegetables and fruit need a different (higher) water quality than the farmers that grow traditional crops. This implicates a differentiation in the type of freshwater that is requested.

During the first workshop it appeared that based on available knowledge, it was not possible to label issues either as a chance or a bottleneck. In particular, more information was needed to assess whether solutions would be robust on the long-term (2030) and how to reallocate the unused potential water in practice. Various knowledge questions were formulated and addressed in sector-specific meetings. In these meetings, existing expert knowledge was integrated with practical knowledge. Answering the knowledge questions took more time than expected, because of underlying conflicting interests that needed to be discussed first.

At the beginning of this process, various stakeholders were all striving for a solution for their specific problems. During the discussion, stakeholders started to realize that the areas depended on each other for their freshwater supply and they started to look for a solution that would integrate various interests. The role of governmental actors in this discussion was the introduction of boundary conditions related to their decision-making. Examples of introduced boundary conditions are: safeguarding specific landscape features by Min. LNV and safeguarding efficient freshwater use by Min. LNV and Min. V\&W. The development period resulted in area-specific solutions, including estimates of costs and benefits. These

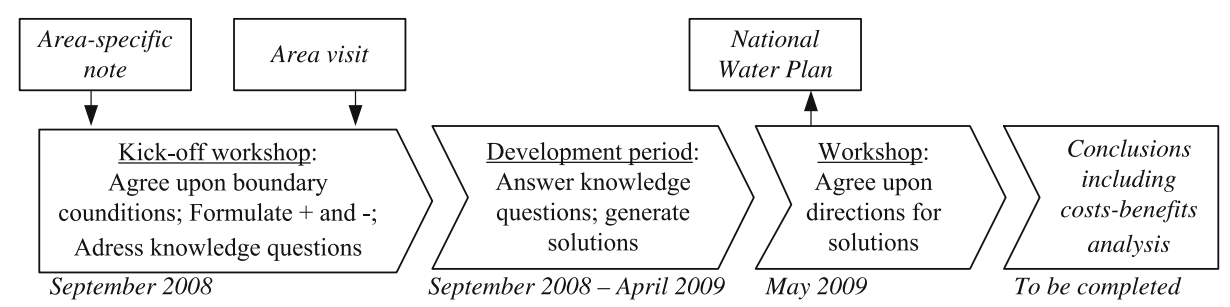

Fig. 5 Rounds of interaction for the sub-discussion in area III 
solutions were reflected upon during the last workshop and resulted in an agreement to include these solutions in the advice from the Delta Steering Group (DSG 2009), which is used as input for the National Water Plan. Although an agreement was reached, there is still a need to finalize this with an agreement (or covenant) which will include the distribution of costs and benefits.

\section{Results and discussion: design and management of stakeholder involvement}

\section{Process of problem structuring}

Both case studies started with an unstructured problem. Context-specific knowledge was lacking and because of this knowledge was uncertain. In case 1, stakeholders also disagreed upon existing knowledge. Both cases are characterized by disagreement concerning the value of either ecology or agriculture in the area. Although, because of these uncertainties and disagreement, it was not possible to formulate one objective, it was possible to define a common basis. This common basis was the process design (Fig. 3), which is based on the principle of moving from substantive variety to selection (cf. De Bruijn et al. 2002). The benefit of this design is that it allows for creativity in the beginning, but that it also works towards integration to ensure there is a common basis for the next round of interaction. Case 1 clearly shows that it is important to start with an agreed upon process design, including the scenarios to be discussed. What appears to be irrelevant is that all stakeholders agree upon the content, e.g. available expert knowledge. This confirms the basic idea underlying process or network management approaches to problem solving, which is that early fixations of problem formulations, solutions and objectives should be prevented. Rather, stakeholders should in an interactive process develop a joint image of the problem in order to arrive at some agreement (De Bruijn et al. 2002; Koppenjan and Klijn 2004). Only if a process starts with an open problem formulation, stakeholders can actually contribute to the structuring of a problem.

Both cases confirm the need to develop context-specific knowledge (Eshuis and Stuiver 2005). Many studies were available, but did either not provide an answer to the specific knowledge questions or did not match stakeholders' perceptions. Hence, there was a clear need to integrate expert knowledge with practical knowledge. To create negotiated knowledge, it appeared to be essential that knowledge was shared and discussed with all stakeholders. The project team always aimed at transparency about available knowledge and about how it was generated and integrated. This was done by starting with a note on existing studies to make sure that all participants had the same state-of-the-art knowledge. When new knowledge was developed in sector-specific groups the project team made sure that it was laid down in documents that were spread and discussed among other participants. This confirms that being transparent about the process and its management is an important principle for interactive processes (cf. De Bruijn et al. 2002). Also, it is important to acknowledge that the process manager does not always have full control over the knowledge production of other parties involved. However, they do and should control the knowledge distribution among the stakeholders in the process.

In both cases the problem formulations of stakeholders involved developed during the interactive process. These developments can be explained by both strategic and cognitive learning (Koppenjan and Klijn 2004). The case studies show that providing information is only one aspect that enhances learning. More crucial are two forms of interaction: among stakeholders with diverging perceptions and among stakeholders with similar perceptions. 
The first type of interaction is also referred to as 'cross-frame reflection' (Koppenjan and Klijn 2004). Interaction between stakeholders with different frames was enhanced during the field visit and the analysis of chances and bottlenecks. We observed that this helped stakeholders to get a better understanding of other 'perceptions of reality' (Van de Riet 2003). This interaction thus widened stakeholders' problem formulations. The field visit also visualized the problem. For both cases, this round of interaction was followed by a development phase (see Figs. 4 and 5) in which like-minded stakeholders-with assistance from the project team-developed new knowledge. This helped to deepen their knowledge of the problem (cognitive learning, Fig. 6).

As stakeholders have different interests and objectives, they will never arrive at identical problem formulations. What is therefore needed to arrive at an agreement is that stakeholders become aware of their mutual dependencies (strategic learning, Fig. 6). In case 1, stakeholders realized by the end of the last workshop that it would strengthen their position as a group to agree upon one solution. The progress of the Planning Study VZ-lake and pressure from the project team and some leading stakeholders certainly played a role in this. In case 2, the future of the VZ-lake was much more certain. Because of this, the objectives of stakeholders were less conflicting. The strategic learning observed in case 2 is that stakeholders widened their problem formulations and became aware of the larger picture. This made them look for integrated and long(er) term solutions. Both strategic and cognitive learning are needed to arrive at 'negotiated knowledge'. The case studies show that this can be enhanced by organizing interaction within and between actor groups and by actively involving stakeholders in knowledge development. In other words, "negotiated knowledge results from a process to which parties have contributed their own information and values" (De Bruijn et al. 2002 p. 20).

\section{Management of contextual factors}

What characterized the direct context of both case studies is that water problems were connected to important functions of the area. This meant that stakeholders with conflicting interests were involved, which necessitated a problem-structuring approach. If the project would not have been taken this multi-actor setting into account, it may still have resulted in

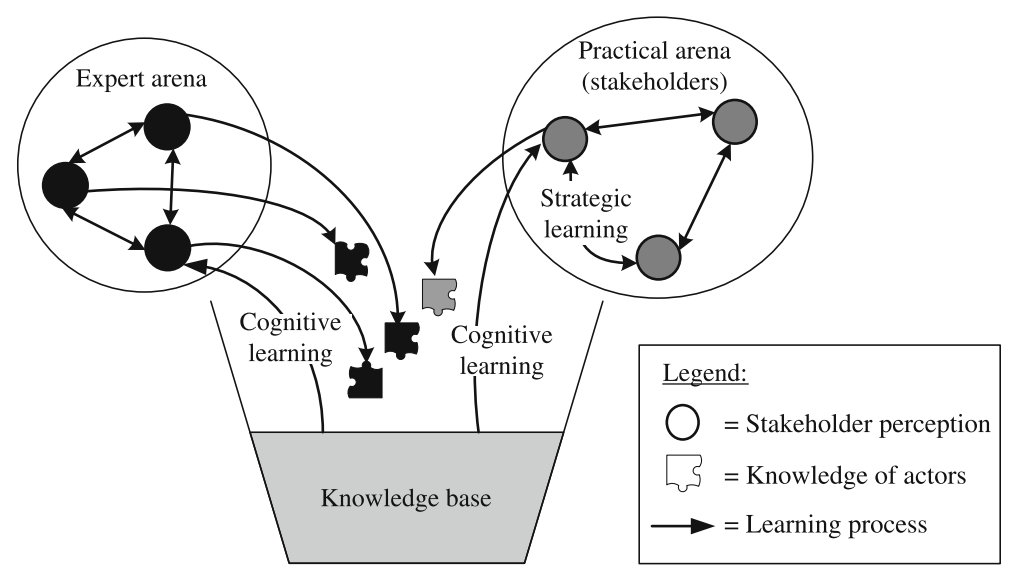

Fig. 6 Relation between knowledge of experts and stakeholders and learning in problem structuring (Hommes et al. 2009b) 
valid, context-specific knowledge. However, it would not have been agreed upon by all relevant stakeholders (Hommes et al. 2009a). What differed in the project-specific context of the cases was that case 1 was the first sub-discussion in a series, whereas case 2 was already preceded by two sub-discussions (see Table 1). This means that in case 2, the outcomes of previous discussions was taken into account. This prevented fragmentation of decision-making, which is usually a problem. In the integration document (DSG 2009) area I and II are even seen as 'one area'.

The fundamental discussion was part of an ongoing political debate on re-establishment of estuarine dynamics in the Delta. From a political perspective, the fundamental discussion is an attempt of responsible ministries to create support for the implementation of their policy, which focuses on re-establishment of estuarine dynamics. This support has increased as local stakeholders came up with solutions for the freshwater supply in the area. These solutions, and the decision to re-establish estuarine dynamics in the VZ-lake, are all included in the approved National Water Plan. What strongly influenced case 1 is the Planning Study VZ-lake. First, stakeholders had the impression that they may still be able to influence the study. The project team tried to draw a clear line by excluding all chances and bottlenecks - related to the planning study - from the discussion. The future of the VZlake became clearer by the end of case 1, which helped stakeholders in arriving at one solution. During case 2, the future state of the VZ-lake was already clear; the assignment was now to find freshwater solutions despite a saltwater VZ-lake. For this case, there was a strong incentive to complete the discussion in time, so that the results would be included in the National Water Plan. Ongoing policy processes thus strongly affected the development of both sub-discussions. The role of use and property rights (which is also part of the structural context) was not specifically investigated in the case studies. However, the cases show that (historical) property and use rights may play a significant role. In case 2 , for example, part of the area used to receive water from the VZ-lake (historical use right) and therefore still insisted on compensation if the VZ-lake becomes salt. The distribution of costs and benefits was not yet included in the discussions, but is also strongly related to property and use rights. To arrive at an implementable solution, it is important to pay attention to property and use rights as well.

The project team used criteria similar to Wesselink (2007) to select participants. However, an important difference is that the project team limited the participation of actors that live or work in the area (group 1) to actors whom are directly affected by freshwater supply. The fact that stakeholders involved were directly affected by the issue under concern, meant that they were also knowledgeable on the topic. Further broadening of actor representation would, according to the project team, only be necessary in projects that ask, for example, for creativity. Actor involvement in this case was focused on advising competent authorities. Both cases show that involving knowledgeable stakeholders in structuring a problem can actually result in an advice which is used by the national government in their policy process.

Representatives with a political-administrative role (actor groups 2 and 3) did actively participate in both case studies. Their main role was in setting and communicating relevant political-administrative boundaries. In each case, this role was filled-in in a different manner. In case 1, boundaries were mainly set by the Delta Steering Group during the kickoff. The project team expected that governmental actors would further introduce other relevant boundaries, such as boundaries related to local and regional spatial planning policy. However, this role was not taken up by the representatives of the government. This case actually confirms that it is difficult for governmental actors to commit themselves to interactive processes and to play a constructive role (Klijn and Koppenjan 2000). It also 
reveals that this is not just the case for elected politicians, but also for civil servants. On account of these experiences, the project team decided to pay more attention to linking the interactive process to existing governance structures in case 2 . They ensured the active involvement of governmental actors by organizing specific moments to discuss the process progress. Whereas in case 1 the participation of governmental actors was mostly limited to civil servants, in case 2 there was also more contact with politicians. It certainly helped that there was a political sense of urgency as the National Water Plan was drafted. It is concluded that although the increased commitment is partly caused by external factors, it also helped that process managers put an additional effort in involving them.

\section{Conclusions}

This paper presents two case studies in which the distribution of freshwater is integrated with spatial development in the southwestern Delta in the Netherlands. Both case studies are concrete examples of how IWRM was put in practice. The case studies confirm that IWRM projects tend to start with uncertain, and sometimes disagreed upon, knowledge and diverging perceptions. Dealing with such problems asks for the initiation of a problemstructuring or learning-oriented process. By organizing this, it is possible to arrive at 'negotiated knowledge', i.e. a knowledge base for which stakeholders agree about its validity and about its significance and meaning. Although such approach is not obliged for the implementation of European directives, such as the Water Framework Directive, complex projects certainly benefit from it.

The case studies show how disagreement and uncertainty can be dealt with in a process of problem structuring. First of all, all participants should, despite their diverging perceptions, agree upon the process design. The process design itself should enhance actors to communicate and interact with each other and to contribute with their practical knowledge. This enhances two types of learning processes: cognitive and strategic learning. Cognitive learning refers to cross-frame reflection (among stakeholders with diverging perceptions) or deepening of stakeholders' knowledge (among stakeholders with similar perceptions). Strategic learning means that stakeholders become aware of their mutual dependencies. Both types of learning processes are needed to create negotiated knowledge. Furthermore, integration of practical knowledge and expert knowledge is needed to create a context-specific, valid knowledge that matches stakeholders' perceptions. It is crucial that this negotiated knowledge is created in a transparent manner. This can be achieved by ensuring that all existing and newly developed knowledge is laid down in visible products which are spread among participants, so that they can be discussed.

To analyze the role of contextual factors, a distinction was made between the projectspecific, structural and wider context. The cases show that the contextual setting is highly dynamic and may strongly influence the process developments. This means that process management should be flexible and adaptive. As regards the stakeholder involvement, this was limited to people that were directly affected by the issues and knowledgeable; it thus excluded the general public. Particular attention should be given to the involvement of governmental actors. This involvement should not be limited to civil servants; process managers should also strive for the commitment of politicians. This can be done by organizing specific moments in which governmental actors are informed about progress made.

Acknowledgements The authors thank TNO, the process managers and process participants from our case studies. Also, we thank Stephanie Janssen of Deltares for her helpful comments on previous versions of this paper. 
Open Access This article is distributed under the terms of the Creative Commons Attribution Noncommercial License which permits any noncommercial use, distribution, and reproduction in any medium, provided the original author(s) and source are credited.

\section{References}

Abdeldayem S, Hoevenaars J, Mollinga P, Scheumann W, Slootweg R, Steenbergen F (2005) Agricultural drainage: towards an integrated approach. Irrig Drain Syst 19(1):71-87. doi:10.1007/s10795-005-2974-5

Abels G (2007) Citizen involvement in public policy-making: does it improve democratic legitimacy and accountability? The case of pTA. Interdiscip Inf Sci 13(1):103-116

Bressers HTA (2009) From public administration to policy networks: contextual interaction analysis. In: Nahrath S, Varone F (eds) Rediscovering public law and public administration in comparative policy analysis: tribute to Peter Knoepfel. Haubt Verlag Ag, Bern

Bressers H, Kuks S (2004) Integrated governance and water basin management: conditions for regime change towards sustainability. Kluwer Academic Publishers, Dordrecht

De Bruijn H, Ten Heuvelhof EF, In't Veld RJ (2002) Process management: why project management fails in complex decision making processes. Kluwer Academic Publishers, Dordrecht

Dewulf A, Craps M, Bouwen R, Taillieu T, Pahl-Wostl C (2005) Integrated management of natural resources: dealing with ambiguous issues, multiple actors and diverging frames. Water Sci Technol 52(6): $115-124$

DSG (2009) Zoet water Zuidwestelijke Delta: Een voorstel voor een regionale zoetwatervoorziening (Freshwater Southwestern Delta: a proposal for regional freshwater supply). Stuurgroep Zuidwestelijke Delta. http://www.zwdelta.nl/nl/downloads.htm. Accessed 24 September 2009

Eshuis J, Stuiver M (2005) Learning in context through conflict and alignment: farmers and scientists in search of sustainable agriculture. Agric Human Values 22(2):137-148. doi:10.1007/s10460-004-8274-0

European Commission (2003) Common Implementation Strategy for the Water Framework Directive (2000/60/EC); Guidance document no 8: Public Participation in relation to the Water Framework Directive. Office for Official Publications of the European Communities. http://circa.europa.eu/Public/irc/env/wfd/library?1=/framework directive/guidance_documents/guidancesnos8spublicspar/EN_1.0_\&a=d. Accessed 18 February 2010

Gummesson E (2000) Qualitative methods in management research, 2nd edn. Sage Publications, Thousand Oaks

Hisschemöller M (2005) Participation as knowledge production and the limits of democracy. In: Maasen S, Weingart P (eds) Democratization of expertise? Exploring novel forms of scientific advice in political decision-making. Springer, Dordrecht, pp 189-208

Hommes S (2008) Conquering complexity: dealing with uncertainty and ambiguity in water management. Dissertation, University of Twente

Hommes S, Hulscher SJMH, Mulder JPM, Otter HS, Bressers HTA (2009a) Role of perceptions and knowledge in the impact assessment for the extension of Mainport Rotterdam. Mar Policy 33:146-155. doi:10.1016/j.marpol.2008.05.006

Hommes S, Vinke-de Kruijf J, Otter HS, Bouma G (2009b) Knowledge and perceptions in participatory policy processes: lessons from the delta-region in the Netherlands. Water Resour Manag 23(8):16411663. doi:10.1007/s11269-008-9345-6

Klijn EH, Koppenjan JFM (2000) Politicians and interactive decision making: institutional spoilsports or playmakers. Publ Adm 78(2):365-387

Kolkman MJ, Kok M, van der Veen A (2005) Mental model mapping as a new tool to analyse the use of information in decision-making in integrated water management. Phys Chem Earth 30(4-5):317-332. doi:10.1016/j.eiar.2007.05.005

Koppenjan JFM, Klijn E (2004) Managing uncertainties in networks: a network approach to problem solving and decision making. Routledge, London

Min. V\&W (2007) Safeguarding our future: the government's vision of national water policy. Ministerie van Verkeer en Waterstaat. http://www.verkeerenwaterstaat.nl/english/topics/water/water_and_the_future/ water_vision/. Accessed 24 September 2009

Min. V\&W (2009) Nationaal Waterplan 2009-2015 (Design National Waterplan). Ministerie van Verkeer en Waterstaat. http://www.verkeerenwaterstaat.nl/Images/NWP_tcm195-270588.pdf. Accessed 18 February 2010

Min. VROM, LNV, VenW, and EZ (2004) Nota Ruimte: Ruimte voor ontwikkeling (National Spatial Strategy: Space for development). Ministerie van VROM. http://www2.vrom.nl/notaruimte/. Accessed 24 September 2009

Provincie Zeeland (2003) De Delta in Zicht: Een integrale visie op de Deltawateren (The Delta in Sight: An integrated vision on the Deltawaters). Provincie Zeeland. www.delta-wateren.nl/phpimg/rapporten_2_0a_ Delta_inZicht.pdf. Accessed 24 Sept 2009 
Schön DA, Rein M (1994) Frame reflection: toward the resolution of intractable policy controversies. Basic Books, New York

Van de Riet AWT (2003) Policy analysis in multi-actor policy settings: navigating between negotiated nonsense and superfluous knowledge. Dissertation, Delft University of Technology

Wesselink AJ (2007) Integraal waterbeheer: De verweving van expertise en belangen (Integration in water management: the interweaving of expertise and interests). Dissertation, University of Twente

Yin RK (2009) Case study research: design and methods, 4th edn. Sage Publications, Thousand Oaks 